\title{
Correlation of West Nile Virus Incidence in Donated Blood with West Nile Neuroinvasive Disease Rates, United States, 2010-2012
}

\author{
Edouard Betsem, Zhanna Kaidarova, Susan L. Stramer, Beth Shaz, Merlyn Sayers, \\ German LeParc, Brian Custer, Michael P. Busch, Edward L. Murphy
}

\begin{abstract}
Over the past decade, West Nile virus (WNV) has spread across the United States. We aggregated blood donor data from 2010-2012 and then calculated the incidence of WNV RNA-positive donations and compared the incidence with neuroinvasive disease (NID) case data from the ArboNET surveillance system. Of 10,107,853 donations, 640 were confirmed positive. The seasonal WNV incidence rate per 100,000 persons was $33.4(95 \% \mathrm{Cl} 22-45)$ in 2010, 25.7 $(95 \% \mathrm{Cl} 15-34)$ in 2011 , and 119.9 (95\% Cl 98-141) in 2012. NID to blood donor ratios were 1 in $164(95 \% \mathrm{Cl}$ 152-178) in 2010, 1 in 158 (95\% Cl 145-174) in 2011, and 1 in $131(95 \%$ Cl 127-136) in 2012. We updated estimates of the ratio of NID to WNV infection rates, demonstrating stable disease penetrance over the study period. Blood donor WNV RNA screening is a valuable public health tool for WNV surveillance.
\end{abstract}

$\mathrm{W}$ est Nile virus (WNV), a mosquitoborne flavivirus, was first isolated in 1937 from a patient in Uganda (1). The virus was introduced into the United States in 1999, resulting in a focal epidemic that year in New York, New York. WNV then made a westward migration across the United States, becoming an endemic public health problem that is monitored through the Centers for Disease Control and Prevention (CDC; Atlanta, GA, USA) ArboNET surveillance system (2). Although most WNV infections

Author affiliations: University of Yaounde 1 Faculty of Medicine and Biomedical Sciences, Yaounde, Cameroon (E. Betsem);

Agence de Médecine Préventive, Bobo-Dioulasso, Burkina Faso

(E. Betsem); Blood Systems Research Institute, San Francisco,

California, USA (E. Betsem, Z. Kaidarova, B. Custer, M.P. Busch,

E.L. Murphy); American Red Cross, Gaithersburg, Maryland, USA

(S.L. Stramer); New York Blood Center, New York, New York, USA

(B. Shaz); Carter BloodCare, Bedford, Texas, USA (M. Sayers);

University of Texas Southwestern Medical Center, Dallas, Texas,

USA (M. Sayers); OneBlood, St. Petersburg, Florida, USA

(G. LeParc); University of California, San Francisco (B. Custer,

M.P. Busch, E.L. Murphy)

DOI: http://dx.doi.org/10.3201/eid2302.161058 are asymptomatic, they can cause a syndrome of fever and myalgia in a minority of cases and can also cause neuroinvasive disease (NID) manifesting as meningitis, encephalitis, or acute flaccid paralysis (2-6). An estimated 20\%$25 \%$ of infected persons become symptomatic (5). During 1999-2010, an estimated 2-4 million WNV infections, $0.4-1$ million cases of febrile illness, and 13,000 reported cases of NID occurred in the United States (7). US public health authorities received $>39,000$ reports of WNV infections during 1999-2013 (8). Early data from 1999 indicated that NID develops in $<1$ in $150 \mathrm{WNV}$-infected persons (5). However, based on 2003 data, this estimate was revised to 1 in 256 based on a correlation of NID case-report data with total WNV infection projections derived from blood donor WNV testing data (9).

The risk of transmitting WNV through blood transfusion was anticipated by CDC investigators and estimated to be as high as 2.7 transmissions/10,000 transfused blood units during the peak of the 1999 outbreak (10); however, confirmed transfusion-transmitted infections were not reported until $2002(11,12)$. After these reports, the US Food and Drug Administration, CDC, US blood centers, and test manufacturers quickly collaborated to develop and implement, beginning in summer 2003, routine nucleic acid testing (NAT) to screen blood donors for WNV RNA $(13,14)$.

Predictions of the scale of annual outbreaks are not reliable (7). Environmental temperature and precipitation data may serve to estimate when WNV transmission rates in mosquitoes and birds will exceed specific thresholds, such that the probability of transmission to humans would be predicted to occur $(15,16)$. Blood center data are a useful adjunct because testing laboratories monitor the number of WNV NAT-positive donations in near real time to determine if they should convert from NAT of minipools (MP-NAT) to more sensitive NAT of individual donations (ID-NAT) (17). In addition, WNV NAT-positive blood donations and NID cases are reported to CDC by state and territorial health laboratories via the ArboNET surveillance system. These reports showed that, after relatively low numbers of WNV outbreaks 
during 2004-2011, the WNV incidence rate in 2012 was one of the highest reported. The NID-associated death rate in 2012 was $9.9 \%$, and the number of deaths (286) is the highest annual number reported to CDC; of the 286 deaths, $55.5 \%$ (159) were reported from 5 states: 89 (31\%) from Texas, 20 (7\%) from California, 16 (5.6\%) in Louisiana, and 17 (6\%) each from Michigan and Oklahoma (18).

Blood donors represent a readily accessible sample of the US population that is systematically screened for incident WNV infections. This screening provides an approximation of the magnitude of the WNV epidemic each year, and this estimate complements data reported to ArboNET on cases of symptomatic WNV-associated disease. Busch et al. (9) previously estimated national and state-specific WNV infection rates in 2003 from the number and frequency of WNV NAT-positive blood donations and used those rates to provide statewide projections, which were then correlated with NID case rates. In this study, we used a larger dataset of WNV NAT-positive blood donations to model the US population incidence of WNV during 2010-2012. We also provide updated ratios of the estimated number of WNV infections to NID cases.

\section{Methods}

\section{Study Population}

Blood donor data were extracted from operational blood center databases and provided without personal identifiers. The total number of donations and the number of NATconfirmed WNV-positive donations were categorized by donor age, sex, and state of residence. Data were collected over the 5-month epidemic period from June 1 to October 31 during 2010-2012. During 2003-2012, only 5 WNV NAT-positive blood donations were reported outside the months (June-October) that we included in this analysis: 4 occurred in November 2012 and 1 in April 2010 (19). Data for this study were obtained from the American Red Cross (Washington, DC, USA), which collects blood in 44 US states and Washington, DC; Blood Systems, Inc. (Scottsdale, AZ, USA), whose centers collect mostly in the Southwest, the Central Plains, and parts of California; the New York Blood Center (New York, NY, USA), which collects in New York and New Jersey; Carter Blood Care (Bedford, TX, USA), which collects in northern Texas; and OneBlood (Tampa, FL, USA), which collects blood throughout Florida and southern Georgia. Altogether, the current dataset is estimated to capture $\approx 60 \%$ of US blood donations. Blood centers provided count data stratified by age, date of donation, sex, and geographic location, and Blood Systems, Inc. provided person-specific data on all donors to enable risk factor analysis. This analysis did not constitute human subjects research because only existing data without personal identifiers were available to the investigators.

\section{Blood Donor Screening}

During the time of the study, blood donations from Blood Systems, Inc., the New York Blood Center, and Carter Blood Care were tested at Creative Testing Solutions laboratories (Tempe, AZ, USA) for WNV RNA by minipool NAT (pools of 16) and ID-NAT for resolution of donations within reactive pools, both using transcriptionmediated amplification (TMA) (Hologic, San Diego, CA, USA; Grifols Diagnostics, Emeryville, CA, USA). The American Red Cross performed WNV NAT at its National Testing Laboratories (Stockbridge, GA, USA) using the same TMA assay. OneBlood used MP-NAT (pools of 6) based upon a PCR technique (Roche Molecular Systems, Branchburg, NJ, USA) or MP-NAT (pools of 16; Hologic/ Grifols); resolution of donations within reactive pools was done using ID-NAT. Results from MP-NAT testing are monitored to determine if epidemic activity requires the triggering of more sensitive ID-NAT testing in geographic areas experiencing outbreaks $(17,20-25)$. The trigger for converting from MP-NAT to ID-NAT in response to ongoing WNV activity was 1-2 reactive blood donations; for the TMA system, this was restricted to those reactive donations having a high ID-NAT signal $(17,25,26)$.

NAT-reactive blood donations can represent a WNVinfected donor or a falsely reactive test result; thus, results must be confirmed by repeating NAT on an independent sample, by demonstrating donor seroconversion, or both $(17,25)$. In our study, we included all ID-NAT-confirmed positive donations whether they were initially screened by MP-NAT or ID-NAT.

\section{Statistical Analysis}

Using only Blood Systems, Inc., data for confirmed WNVpositive and negative donations, we performed a univariate analysis of WNV NAT reactivity by donation year and donor sex and age group. We compared categorical variables by using the $\chi^{2}$ test; age as a continuous variable was compared using the Student $t$-test. We estimated odd ratios in a logistic regression model that included adjustment for age group, sex, region of residence, season, and month.

Most WNV RNA-positive persons who donate blood are asymptomatic or in the presymptomatic stage of infection; thus, we calculated the seasonal incidence of WNV on the overall dataset, assuming independence between blood donation and WNV infection $(25,27,28)$. For this analysis, we used WNV RNA detection periods (i.e., number of days between first testing positive and testing negative) of $\approx 10.7$ days by MP-NAT and $\approx 19.6$ days by ID-NAT (29). These estimates were adapted from the method of Busch et al. (9), using data from Kleinman et al. (30). We did not have access to data on whether donations were screened by MPNAT or ID-NAT. Given that roughly equal proportions of yield donations were derived from MP-NAT and ID-NAT 
screening, we used an average window of 15.1 days, assuming a $50 \%$ mixture of ID-NAT and MP-NAT screening donations during the epidemic period. We then multiplied the total donations screened for WNV RNA by 15.1 days to derive person-time for the denominator in incidence calculations; the number of corresponding NAT yield donations was used as the numerator (9).

We derived the monthly WNV incidence in each state from June through October by multiplying the number of NAT-positive donations for each month by the number of days in each month and dividing by the average period of time during which RNA is detectable (9). We calculated state-specific seasonal WNV incidence by adding the 5 monthly WNV incidence estimates for each year. An estimation of the number of WNV infections in each state was calculated by multiplying each state-specific seasonal WNV incidence by the corresponding population estimate obtained from the US Census Bureau (31). We then obtained a national seasonal estimate by summing over the estimates for participant states. An overall seasonal incidence for the 3 years was calculated weighted on the general population for each year. CIs were obtained assuming a Poisson distribution for NAT-positive donations.

We obtained the ratio of WNV infections to reported NID cases by state by dividing the estimated number of infections in the general population by state by the number of NID cases reported to ArboNET. This estimation was repeated for each year. We obtained CIs by applying Taylor series expansion (32). Analysis of correlation between WNV incidence and reported NID through ArboNet surveillance was done using a linear regression. Correlations and summarizations were expressed using $\mathrm{R}^{2}$. All statistical analyses were performed using Stata 12.1 (StataCorp
LP, College Station, Texas, USA). We prepared graphical (maps) displays of results using ArcGIS version 9.3.1 (ESRI, Redlands, CA, USA). We did not conduct a countylevel analysis.

\section{Results}

\section{Study Population and Demographic Predictors}

A total of $10,107,853$ blood donations collected during June-October in 2010-2012 were included in this study: total donations for 2010 were $3,470,405$, total donations for 2011 were 3,360,443, and total donations for 2012 were $3,277,005$. All donors included in the analysis were US residents; $20 \%$ lived in Western states, $27 \%$ in the Midwestern states, $32 \%$ in Southern states, and $21 \%$ in Northeastern states. Data from Blood Systems, Inc., indicated that blood donors ranged in age from 16 to 98 years (median age 45 years), and men accounted for $53 \%$ of donations.

Overall, 640 donations were WNV NAT positive (Figure 1). WNV RNA-positive blood donations clustered according to WNV epidemic activity and the catchment areas of the participating blood collection networks. Apparent clustering was observed in Southwest, Central, and Northeast states in 2010 and in Southwest and Northeast states in 2011; the pattern was much more dispersed in 2012, involving the North Central, Southwest, and Northeast states.

The frequency of WNV RNA was $63 \%$ higher among male than female donors and $122 \%$ higher among white than nonwhite donors. Donors from the Midwest had higher rates of WNV infection. Higher rates of NATpositive donations were observed in 2012 versus 2010, but rates in 2011 were significantly lower than those in 2010 (Table).

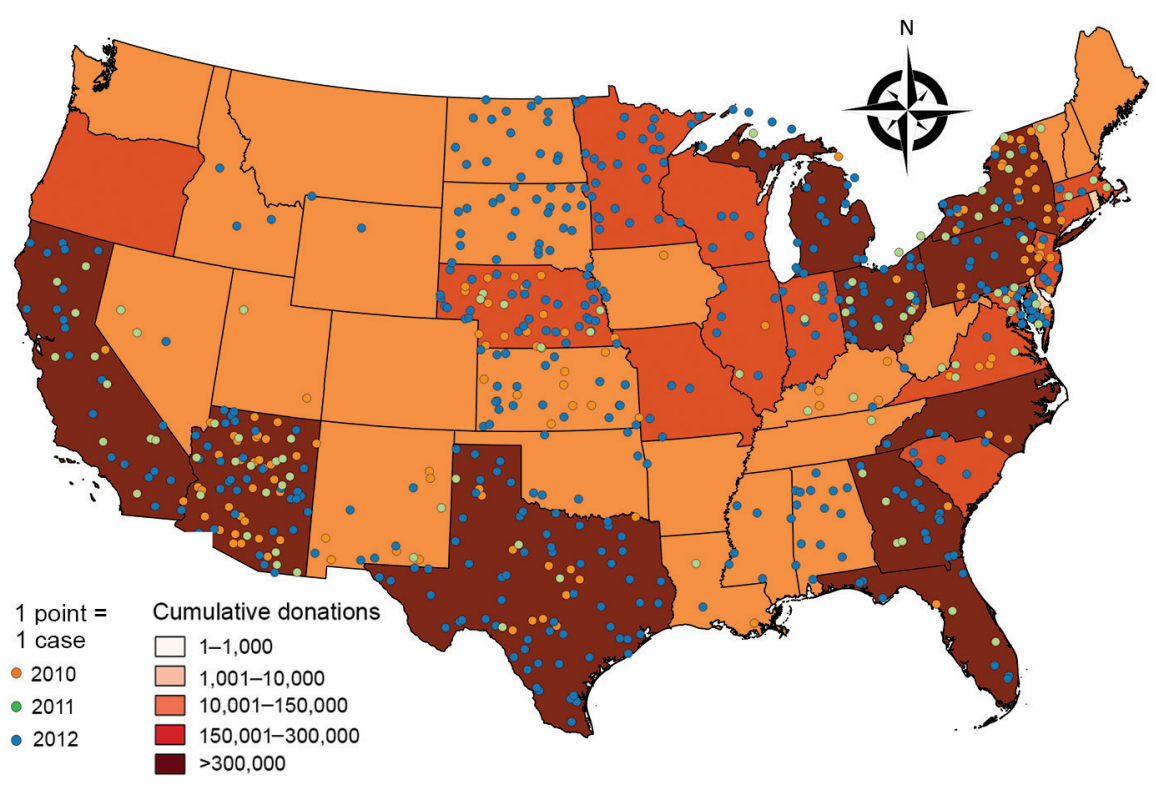

Figure 1. Geographic distribution of blood donations confirmed positive for West Nile virus (WNV) RNA, United States, JuneOctober 2010-2012. The 640 confirmed WNV DNA-positive donations are represented by dots. Shading indicates cumulative number of donations for 20102012, by state, for catchment areas of $\geq 1,000$ donations. 
Table. Demographic characteristics of WNV RNA-positive persons who donated blood during WNV seasons, United States, 2010-2012*

\begin{tabular}{|c|c|c|c|}
\hline Characteristic & No. WNV NAT-positive/no. total (\%) & Crude OR $(95 \% \mathrm{Cl})$ & Adjusted OR $(95 \% \mathrm{Cl})$ \\
\hline \multicolumn{4}{|l|}{ Age group } \\
\hline$\leq 20$ & $13 / 154,874(0.01)$ & Referent & Referent \\
\hline $21-29$ & $17 / 172,947(0.01)$ & $1.17(0.56-2.41)$ & $0.96(0.42-2.20)$ \\
\hline 30-39 & $27 / 164,611(0.02)$ & $1.95(1.01-3.78)$ & $1.63(0.74-3.58)$ \\
\hline $40-49$ & $27 / 205,907(0.01)$ & $1.56(0.80-3.02)$ & $1.31(0.60-2.86)$ \\
\hline$\geq 50$ & $68 / 498,320(0.01)$ & $1.62(0.89-2.94)$ & $1.21(0.58-2.51)$ \\
\hline \multicolumn{4}{|l|}{ Sex } \\
\hline $\mathrm{F}$ & $54 / 566,850(0.01)$ & Referent & Referent \\
\hline $\mathrm{M}$ & $98 / 629,809(0.02) t$ & $1.63(1.17-2.27)$ & $1.59(1.13-2.22)$ \\
\hline \multicolumn{4}{|l|}{ Race } \\
\hline Nonwhite & $20 / 280,246(0.01)$ & Referent & Referent \\
\hline White & $131 / 826,704(0.02)$ & $2.22(1.38-3.55)$ & $1.75(1.06-2.89)$ \\
\hline \multicolumn{4}{|c|}{ Region of residence } \\
\hline Northeast & $0 / 900$ & Omitted & Omitted \\
\hline West & $75 / 765,873(0.01)$ & Referent & Referent \\
\hline Midwest & $44 / 141,507(0.03)$ & $3.17(2.18-4.60)$ & $2.54(1.73-3.73)$ \\
\hline South & $33 / 288,379(0.01)$ & $1.16(0.77-1.75)$ & $1.11(0.73-1.70)$ \\
\hline \multicolumn{4}{|l|}{ Year } \\
\hline 2010 & $44 / 413,840(0.01)$ & Referent & Referent \\
\hline 2011 & $18 / 399,980$ & $0.42(0.24-0.73)$ & $0.43(0.24-0.74)$ \\
\hline 2012 & $90 / 382,839(0.02)$ & $2.21(1.54-3.17)$ & $2.19(1.52-3.15)$ \\
\hline \multicolumn{4}{|l|}{ Month } \\
\hline June & $5 / 240,481$ & Referent & Referent \\
\hline July & $28 / 238,208(0.01)$ & $5.65(2.18-14.64)$ & $5.44(2.09-14.13)$ \\
\hline August & 76/241,994 (0.03) & $15.10(6.11-37.34)$ & $14.62(5.90-36.18)$ \\
\hline September & 39/236,036 (0.02) & 7.94 (3.13-20.16) & $8.34(3.28-21.20)$ \\
\hline October & $4 / 239,940$ & $0.80(0.21-2.98)$ & $0.83(0.22-3.11)$ \\
\hline
\end{tabular}

\section{WNV Seasonal Incidence Analysis}

Seasonal rates were 3.7 cases $/ 100,000$ donations $(\approx 1$ in $26,700)$ in $2010,2.6$ cases $/ 100,000$ donations in $2011(\approx 1$ in 38,200$)$, and 12.9 cases $/ 100,000$ donations $(\approx 1$ in 7,800$)$ in 2012. Over the 3 years, WNV activity was highest in August and September, as evidenced by NAT-positive rates; in 2010 , rates peaked in September $(7.7$ cases $/ 100,000$ donations), and in 2011, rates peaked in August ( 7.0 cases/100,000 donations) (Figure 2). In 2012, NAT-positive rates peaked in August (26.9 cases/100,000 donations), but activity was high from July (16.2 cases/100,000 donations) through September (16.2 cases/100,000 donations).

Diverse geographic incidence patterns were observed over the 3 years (Figure 3). In 2010 and 2011, the states with the highest activity were Arizona, New Mexico, Nebraska, and Kansas; the incidence in 2011 was lower than that in 2010. In 2012, the epidemic grew in scale and expanded to Texas and North Central states, including South Dakota, North Dakota, Minnesota, and Wyoming. High infection incidence was also observed in Alabama and Mississippi.

Overall seasonal WNV incidence estimates were 33.4 cases/100,000 persons in 2010 (online Technical Appendix Table 1, https://wwwnc.cdc.gov/EID/article/23/2/16-1058Techapp1.pdf) and 24.7 cases $/ 100,000$ persons in 2011 (online Technical Appendix Table 2). The estimated incidence for 2012 was 119.9 cases/100,000 persons. Among states, incidence ranged from 12.9 cases/100,000 persons in Virginia to 766.9 and 1,465.4 cases/100,000 persons in
North and South Dakota, respectively (online Technical Appendix Table 3).

National and state-specific variability in projected WNV infections generally paralleled NID rates reported to ArboNET (Figure 3). In 2010, 2011, and 2012, 629, 486, and 2,872 NID cases, respectively, were reported. Cumulative national estimates of WNV cases were 103,450 cases in 2010 and 76,975 cases in 2011, and the ratio of NID cases to WNV infections was 1 to 164 (95\% CI 152-178) in 2010 and 1 to 158 (95\% CI 145-174) in 2011 (Figure

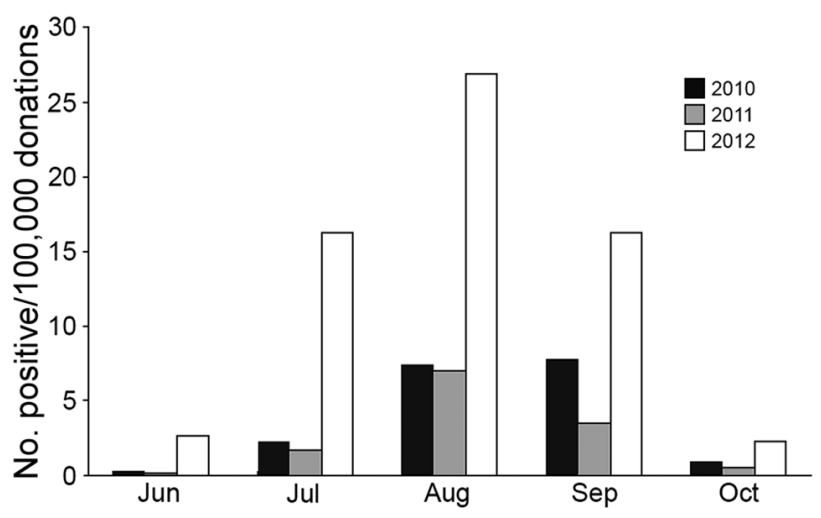

Figure 2. Rate of West Nile virus (WNV)-positive blood donations by month, United States, June-October 2010-2012. Overall, 640 WNV-positive donations were confirmed by nucleic acid testing in 10,107,853 screened donations. Positive donations collected during the months of January-May (1 in April 2010) and November-December (3 in November 2012) are not shown. 

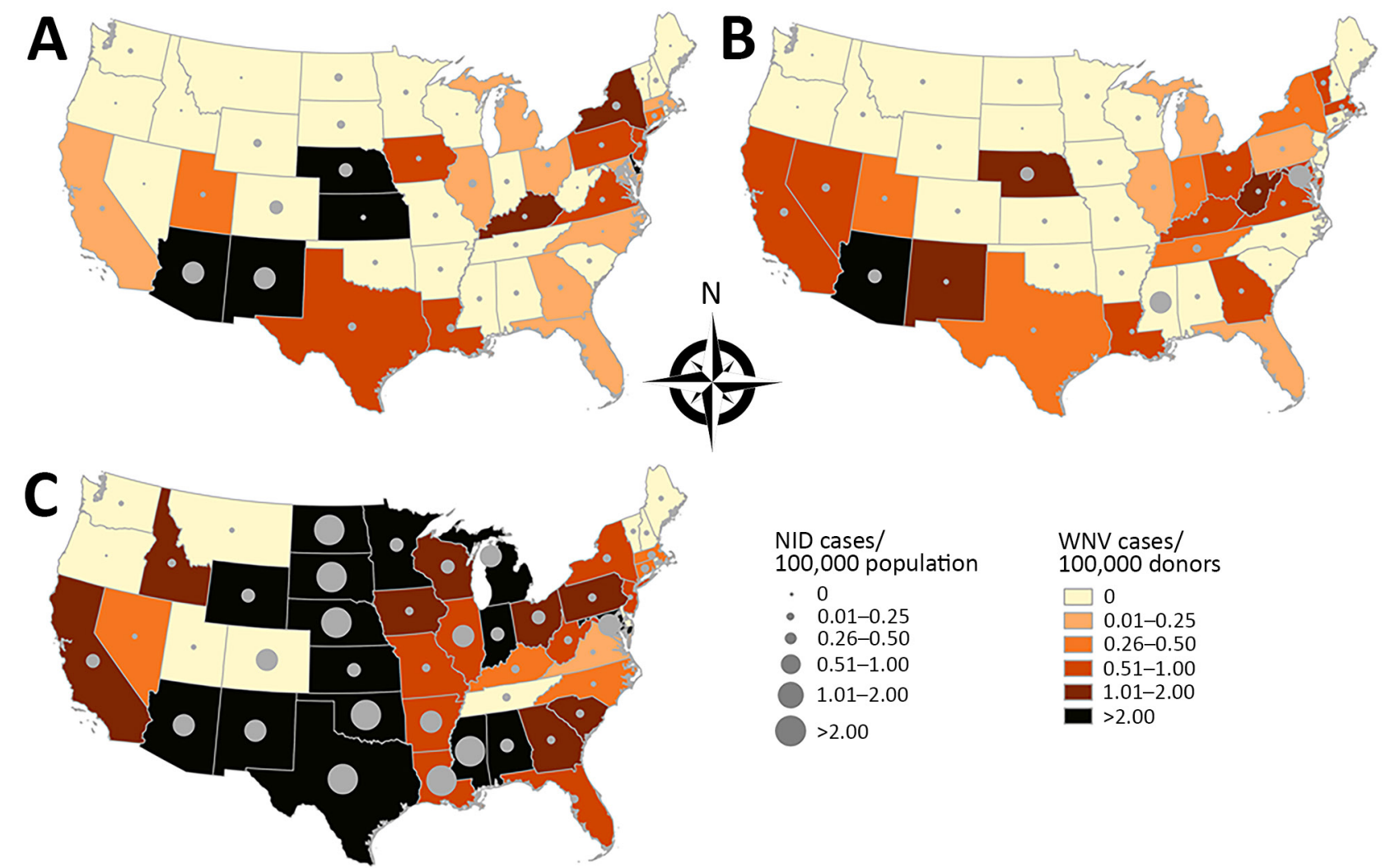

Figure 3. Incidence of West Nile virus (WNV) infection cases and neuroinvasive disease (NID) cases by state, United States, $2010-2012$. Dots indicate attack rates for NID cases reported to the Centers for Disease Control and Prevention in 2010 (A), 2011 (B), and 2012 (C).

4; online Technical Appendix Tables 1, 2). In 2012, an estimated $376,612 \mathrm{WNV}$ infections occurred, and the ratio of NID cases to WNV infections was 1 to 131 (95\% CI 126-136) (Figure 4; online Technical Appendix Table 3). Over the 3 years of the study, the weighted ratio of NID cases to WNV infections in the general population was 1 to 141 (95\% CI 118-164). In addition, during 2010-2012, projected incidence correlated with NID case frequencies $\left(\mathrm{R}^{2}\right.$ value of 0.83 in 2010, 0.83 in 2011, and 0.79 in 2012) (Figure 4).

\section{Discussion}

Our findings, which extended previous findings (9), highlight the value of using WNV NAT-positive blood donation data to model population incidence in the United States. Our period of data collection covered 3 years, including the large WNV epidemic in 2012, enabling us to demonstrate seasonal and geographic variation in incidence. Using a large geographic catchment area and multiple years of data, we were able to provide updated estimates of the ratio of NID cases to WNV infections, demonstrating stable disease penetrance over the study period and that our estimate $(1: 141)$ is closer to that reported for the year $1999(1: 140)$ (5) than that reported for the year 2003 (1:256) (9).
Our analysis of demographic factors shows seasonal and geographic variations of WNV infection rates in blood donors. This study's incidence estimate of 12.9 infections $/ 100,000$ blood donations in 2012 is the same as that reported by Francis et al. (33) for the 2010 outbreak in New York but lower than the 20 and 27 cases $/ 100,000$ persons reported for national data in $2003(9,21)$. Kleinman et al. (20) reported a higher rate of 35 cases $/ 100,000$ blood donations for the 2003 epidemic for a specific group of blood centers. Using American Red Cross data and a well-defined confirmatory algorithm (similar to the method in our study), Stramer et al. (22) reported infection rates of 14.9 and 4.4 cases/100,000 blood donations in 2003 and 2004, respectively; these rates are higher than those we estimated for 2010 and 2011 (3.7 and 2.6 cases/100,000 donations, respectively), but rates in 2003 and 2012 appeared comparable. Projected WNV incidence in the general population and NID case frequency decreased slightly from 2010 to 2011 and then spiked upward in 2012 during an outbreak that spread to the Midwest with high incidence rates (online Technical Appendix Table 3); this pattern was similar to that observed during the 2003 epidemic (http://www.cdc. gov/westnile/resources/pdfs/data/2003stateincidencemap. pdf). These results are in agreement with our data showing 

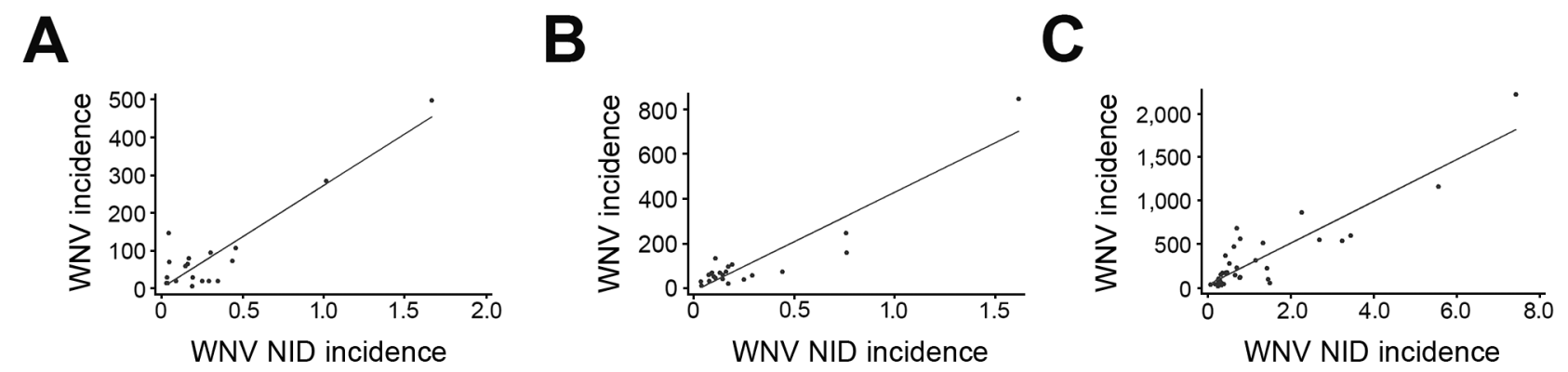

Figure 4. Projected West Nile virus (WNV) incidence (per 100,000 population) versus neuroinvasive disease (NID) case rates (per 100,000 population) by state, United States, 2010-2012. Each dot within each panel represents 1 state. A) Data for 2010 . Data from 30 states were excluded: 11 states with no donors testing positive by nucleic acid testing (NAT) and no NID cases; 17 states with 1-26 NID cases but no NAT-positive donors; and 2 states with 1 and 2 NAT-positive donors, respectively, but no reported NID cases (R2 = 0.83 ). B) Data for 2011. Data from 27 states were excluded: 8 states with neither NAT testing yield nor NID cases and 19 states with 1-31 NID cases but no NAT yield (R2 = 0.83). C) Data for 2012. Data from 15 states were excluded: 3 states with neither NAT testing yield nor NID cases and 12 states with $1-62$ neuroinvasive cases but no NAT yield (R2 = 0.79).

that the highest projected incidence generally correlated with NID case frequencies (Figure 4).

Patterns of WNV activity vary from year to year, exhibiting temporal and geographic variations of incidence, as shown by our data in the blood donor pool and corresponding projections in general population incidence. Fourteen years after their first appearance in the United States, WNV epidemics are still unpredictable and difficult to control (34), as confirmed by the surge of cases in 2012, resulting in 286 reported deaths, after years of relatively mild epidemic years (http://www.cdc.gov/westnile/resources/pdfs/ data/2012wnvhumaninfectionsbystate.pdf).

Previous studies have noted older age and male sex as predictors of severe outcomes (e.g., NID) $(5,35,36)$, but not for detection of WNV RNA, as observed in our study. The strong association that we found with white race/ethnicity is novel and is likely reflective of the fact that more white than nonwhite persons donate blood.

Using data for WNV NAT-positive donors, we estimated that 555,037 WNV infections occurred in the United States during 2010-2012. During that period, ArboNet reported a total of 7,407 NID and non-NID cases (http://www.cdc.gov/westnile/statsmaps/finalmapsdata/ index.html). Busch et al. (9) estimated that 735,000 WNV infections occurred during 2003 in the United States, and ArboNet reported 9,862 NID and non-NID cases in 2003 (http://www.cdc.gov/westnile/resources/pdfs/data/2003wn vhumaninfectionsbystate.pdf). Cervantes et al. (29) reported an estimated 85,156 WNV infections in northern Texas during the 2012 epidemic, compared with our estimate of 93,004 infections in all of Texas that year.

We report a weighted ratio of 1 NID case per 141 WNV infections during 2010-2012, similar to the ratio of 1 NID case per $140 \mathrm{WNV}$ infections reported during the 1999 New York outbreak (5). The difference between our estimate and the estimate reported by Busch et al. ( 9 ) for the year 2003 (1 NID case/256 WNV infections) may reflect yearly variations of the disease, data quality, or, most probably, the differences in the WNV NAT positivity window used in the study by Busch et al. (6.9 days) and in our study (15.1 days), which could have resulted in an overestimate of WNV incidence and NID ratio in 2003. Since the 1999 outbreak in New York, genetic evolution of WNV has been described or hypothesized in the United States and elsewhere with a hypothetical increase in virus fitness and pathogenicity (37-40). The virulent lineage $2 \mathrm{WNV}$ has been implicated in increasing epidemics in Europe and Russia and with devastating cases of NID (41). Our findings do not support a change in virus penetrance in the United States that might have resulted in the higher number of deaths reported during the 2012 season.

The ratio of infection cases to NID cases is a good surveillance strategy for WNV pathogenic evolution. Although issues with case recognition and passive reporting may result in underreporting of NID cases in the general population, data on NID incidence may be more reflective of the total population that is covered by public health surveillance $(2,28)$. On the other hand, decreased public health communication during low-incidence epidemic years could result in underreporting of WNV infections, and increased communication during more severe epidemics could result in more complete reporting.

Strengths of the current study include a very large study population spanning a large geographic region of the United States and a uniform blood donor sampling frame and test methods for WNV RNA. Limitations include geographic gaps in participating blood centers, leading to a potentially biased estimate of incidence in certain states. Blood donor incidence detected by NAT may underestimate infection rates in the general population by as much as $25 \%$ because of self-exclusion from donation due to WNV signs and symptoms (42), resulting in self-selected healthy 
donors. Also, blood collection centers do not draw from entire states, so some areas are proportionally not represented (29). Because we used operational data, we had only a limited number of demographic variables and no information on potential exposures to WNV. Last, because we did not have data on whether MP-NAT or ID-NAT screening was used for each donation, we used an average RNA detection duration period of 15.1 days and, thus, may have slightly underestimated or overestimated WNV incidence (29).

In conclusion, we used a large nationwide dataset obtained from a consortium of blood collection organizations to strengthen the idea that monitoring US blood donations for WNV RNA is a useful surveillance tool for studying the evolution of epidemics and potentially associated pathogenicity. WNV RNA blood donation data are useful for tracking epidemics prospectively (because they are collected in real time) and retrospectively as a complement to existing case-based WNV surveillance networks in the United States.

\section{Acknowledgments}

We are grateful to staff members of the participating blood centers who made these data available.

Financial support was provided by Blood Research Institute (training grant NHLBI K24-75036 to E.L.M.) and the government of Monaco through the Institut Pasteur (training award to E.B.).

Dr. Betsem is managing director of the LAMIVAC at Agence de Médecine Préventive and senior lecturer at the Faculty of Medicine and Biomedical Sciences at the University of Yaounde 1. His research interests are emerging and circulating infectious diseases of viral origin and vaccine-preventable diseases.

\section{References}

1. Smithburn KC, Hughes TP, Burke AW, Paul JH. A neurotropic virus isolated from the blood of a native of Uganda. Am J Trop Med. 1940;20:471-2.

2. Petersen LR, Hayes EB. Westward ho? - The spread of West Nile virus. N Engl J Med. 2004;351:2257-9. http://dx.doi.org/10.1056/ NEJMp048261

3. Centers for Disease Control and Prevention (CDC). Outbreak of West Nile-like viral encephalitis-New York, 1999. MMWR Morb Mortal Wkly Rep. 1999;48:845-9.

4. Gea-Banacloche J, Johnson RT, Bagic A, Butman JA, Murray PR, Agrawal AG. West Nile virus: pathogenesis and therapeutic options. Ann Intern Med. 2004;140:545-53. http://dx.doi.org/10.7326/0003-4819-140-7-200404060-00015

5. Mostashari F, Bunning ML, Kitsutani PT, Singer DA, Nash D, Cooper MJ, et al. Epidemic West Nile encephalitis, New York, 1999: results of a household-based seroepidemiological survey. Lancet. 2001;358:261-4. http://dx.doi.org/10.1016/S01406736(01)05480-0

6. Watson JT, Pertel PE, Jones RC, Siston AM, Paul WS, Austin CC, et al. Clinical characteristics and functional outcomes of West Nile fever. Ann Intern Med. 2004;141:360-5. http://dx.doi.org/10.7326/0003-4819-141-5-200409070-00010
7. Petersen LR, Carson PJ, Biggerstaff BJ, Custer B, Borchardt SM, Busch MP. Estimated cumulative incidence of West Nile virus infection in US adults, 1999-2010. Epidemiol Infect. 2013;141:591-5. http://dx.doi.org/10.1017/S0950268812001070

8. Centers for Disease Control and Prevention. West Nile virus disease cases reported to CDC by state, 1999-2013 [cited 2016 Sep 1]. http://www.cdc.gov/westnile/resources/pdfs/cummulative/99_2013_cummulativeHumanCases.pdf

9. Busch MP, Wright DJ, Custer B, Tobler LH, Stramer SL, Kleinman $\mathrm{SH}$, et al. West Nile virus infections projected from blood donor screening data, United States, 2003. Emerg Infect Dis. 2006;12:395-402. http://dx.doi.org/10.3201/eid1205.051287

10. Biggerstaff BJ, Petersen LR. Estimated risk of West Nile virus transmission through blood transfusion during an epidemic in Queens, New York City. Transfusion. 2002;42:1019-26. http://dx.doi.org/10.1046/j.1537-2995.2002.00167.x

11. Pealer LN, Marfin AA, Petersen LR, Lanciotti RS, Page PL, Stramer SL, et al.; West Nile Virus Transmission Investigation Team. Transmission of West Nile virus through blood transfusion in the United States in 2002. N Engl J Med. 2003;349:1236-45. http://dx.doi.org/10.1056/NEJMoa030969

12. Harrington T, Kuehnert MJ, Kamel H, Lanciotti RS, Hand S, Currier M, et al. West Nile virus infection transmitted by blood transfusion. Transfusion. 2003;43:1018-22. http://dx.doi.org/ 10.1046/j.1537-2995.2003.00481.x

13. Dodd RY. Emerging infections, transfusion safety, and epidemiology. N Engl J Med. 2003;349:1205-6. http://dx.doi.org/ 10.1056/NEJMp038138

14. Centers for Disease Control and Prevention (CDC). Update: detection of West Nile virus in blood donations-United States, 2003. MMWR Morb Mortal Wkly Rep. 2003;52:916-9.

15. Liu A, Lee V, Galusha D, Slade MD, Diuk-Wasser M, Andreadis T, et al. Risk factors for human infection with West Nile Virus in Connecticut: a multi-year analysis. Int J Health Geogr. 2009;8:67. http://dx.doi.org/10.1186/1476-072X-8-67

16. Johnson BJ, Sukhdeo MV. Drought-induced amplification of local and regional West Nile virus infection rates in New Jersey. J Med Entomol. 2013;50:195-204. http://dx.doi.org/10.1603/ME12035

17. Dodd RY, Foster GA, Stramer SL. Keeping blood transfusion safe from West Nile virus: American Red Cross experience, 2003 to 2012. Transfus Med Rev. 2015;29:153-61. http://dx.doi.org/10.1016/j.tmrv.2015.03.001

18. Centers for Disease Control and Prevention. West Nile virus. Final annual maps and data for 1999-2014 [cited 2016 Feb 24]. http://www.cdc.gov/westnile/statsMaps/finalMapsData/index.html

19. AABB. West Nile Virus Biovigilance Network. 2016 [cited 2016 Sep 1]. http://www.aabb.org/research/hemovigilance/Pages/wnv.aspx

20. Kleinman S, Glynn SA, Busch M, Todd D, Powell L, Pietrelli L, et al.; NHLBI Retrovirus Epidemiology Study (REDS). The 2003 West Nile virus United States epidemic: the America's Blood Centers experience. Transfusion. 2005;45:469-79. http://dx.doi.org/10.1111/j.0041-1132.2005.04315.x

21. Busch MP, Caglioti S, Robertson EF, McAuley JD, Tobler LH, Kamel H, et al. Screening the blood supply for West Nile virus RNA by nucleic acid amplification testing. N Engl J Med. 2005;353:460-7. http://dx.doi.org/10.1056/NEJMoa044029

22. Stramer SL, Fang CT, Foster GA, Wagner AG, Brodsky JP, Dodd RY. West Nile virus among blood donors in the United States, 2003 and 2004. N Engl J Med. 2005;353:451-9. http://dx.doi.org/10.1056/NEJMoa044333

23. Custer B, Tomasulo PA, Murphy EL, Caglioti S, Harpool D, McEvoy P, et al. Triggers for switching from minipool testing by nucleic acid technology to individual-donation nucleic acid testing for West Nile virus: analysis of 2003 data to inform 2004 decision making. Transfusion. 2004;44:1547-54. http://dx.doi.org/10.1111/ j.0041-1132.2004.04227.x 
24. Busch MP, Tobler LH, Saldanha J, Caglioti S, Shyamala V, Linnen JM, et al. Analytical and clinical sensitivity of West Nile virus RNA screening and supplemental assays available in 2003. Transfusion. 2005;45:492-9.

25. Zou S, Foster GA, Dodd RY, Petersen LR, Stramer SL. West Nile fever characteristics among viremic persons identified through blood donor screening. J Infect Dis. 2010;202:1354-61. http://dx.doi.org/10.1086/656602

26. AABB. Association bulletin no. 08-03. West Nile virus - revised recommendations for triggering individual donation nucleic acid testing and use of communication plans [cited 2016 Sep 1]. http://www.cdph.ca.gov/programs/lfs/Documents/AABB $\% 20$ WNV\%2004-08.pdf

27. Custer B, Kamel H, Kiely NE, Murphy EL, Busch MP. Associations between West Nile virus infection and symptoms reported by blood donors identified through nucleic acid test screening. Transfusion. 2009;49:278-88. http://dx.doi.org/10.1111/ j.1537-2995.2008.01952.x

28. Orton SL, Stramer SL, Dodd RY. Self-reported symptoms associated with West Nile virus infection in RNA-positive blood donors. Transfusion. 2006;46:272-7. http://dx.doi.org/10.1111/ j.1537-2995.2006.00710.x

29. Cervantes DT, Chen S, Sutor LJ, Stonecipher S, Janoski N, Wright DJ, et al. West Nile virus infection incidence based on donated blood samples and neuroinvasive disease reports, Northern Texas, USA, 2012. Emerg Infect Dis. 2015;21:681-3. http://dx.doi.org/10.3201/eid2104.141178

30. Kleinman SH, Williams JD, Robertson G, Caglioti S, Williams RC, Spizman R, et al. West Nile virus testing experience in 2007: evaluation of different criteria for triggering individual-donation nucleic acid testing. Transfusion. 2009;49:1160-70. http://dx.doi.org/10.1111/j.1537-2995.2009.02127.x

31. United States Census Bureau. US population estimates. 2012 [cited 2012 Jun 15]. http://www.census.gov

32. Dann RS, Koch GG. Review and evaluation of methods for computing confidence intervals for the ratio of two proportions and considerations for non-inferiority clinical trials. J Biopharm Stat. 2004;15:85-107. http://dx.doi.org/10.1081/ BIP-200040844

33. Francis RO, Strauss D, Williams JD, Whaley S, Shaz BH. West Nile virus infection in blood donors in the New York City area during the 2010 seasonal epidemic. Transfusion. 2012;52:2664-70. http://dx.doi.org/10.1111/j.1537-2995.2012.03639.x

34. Petersen LR, Fischer M. Unpredictable and difficult to control - the adolescence of West Nile virus. N Engl J Med. 2012;367:1281-4. http://dx.doi.org/10.1056/NEJMp1210537

35. Petersen LR, Marfin AA, Gubler DJ. West Nile virus. JAMA. 2003;290:524-8. http://dx.doi.org/10.1001/jama.290.4.524

36. Tsai TF, Popovici F, Cernescu C, Campbell GL, Nedelcu NI. West Nile encephalitis epidemic in southeastern Romania. Lancet. 1998; 352:767-71. http://dx.doi.org/10.1016/S0140-6736(98)03538-7

37. Pybus OG, Suchard MA, Lemey P, Bernardin FJ, Rambaut A, Crawford FW, et al. Unifying the spatial epidemiology and molecular evolution of emerging epidemics. Proc Natl Acad Sci U S A. 2012;109:15066-71. http://dx.doi.org/10.1073/ pnas. 1206598109

38. Mann BR, McMullen AR, Swetnam DM, Salvato V, Reyna M, Guzman H, et al. Continued evolution of West Nile virus, Houston, Texas, USA, 2002-2012. Emerg Infect Dis. 2013;19:1418-27. http://dx.doi.org/10.3201/eid1909.130377

39. McMullen AR, Albayrak H, May FJ, Davis CT, Beasley DW, Barrett AD. Molecular evolution of lineage 2 West Nile virus. J Gen Virol. 2013;94:318-25. http://dx.doi.org/10.1099/vir.0.046888-0

40. Añez G, Grinev A, Chancey C, Ball C, Akolkar N, Land KJ, et al. Evolutionary dynamics of West Nile virus in the United States, 1999-2011: phylogeny, selection pressure and evolutionary time-scale analysis. PLoS Negl Trop Dis. 2013;7:e2245. http://dx.doi.org/10.1371/journal.pntd.0002245

41. Bakonyi T, Ferenczi E, Erdélyi K, Kutasi O, Csörgő T, Seidel B, et al. Explosive spread of a neuroinvasive lineage 2 West Nile virus in Central Europe, 2008/2009. Vet Microbiol. 2013;165:61-70. http://dx.doi.org/10.1016/j.vetmic.2013.03.005

42. Petersen LR, Brault AC, Nasci RS. West Nile virus: review of the literature. JAMA. 2013;310:308-15. http://dx.doi.org/10.1001/ jama.2013.8042

Address for correspondence: Edward L. Murphy, Blood Systems Research Institute, 270 Masonic Ave, San Francisco, CA 94118, USA; email: Ed.Murphy@ucsf.edu; Michael P. Busch, Blood Systems Research Institute, 270 Masonic Ave, San Francisco, CA 94118, USA; email: mbusch@bloodsystems.org

\section{PubMed}

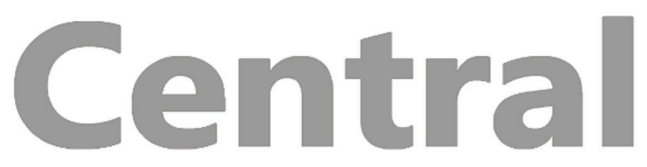

\section{PublMed}

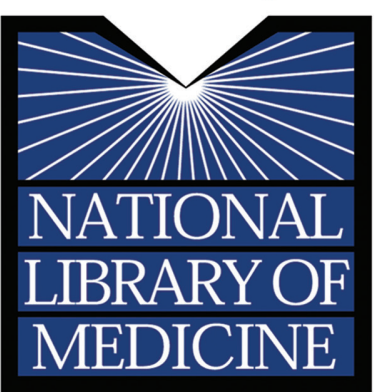

\section{Find Emerging Infectious Diseases content in the digital archives of the National Library of Medicine}

www.pubmedcentral.nih.gov 